\title{
Efektifitas Edukasi Terpadu Dalam Meningkatkan Efikasi Diri Pasien Pasca Operasi Total Hip dan Knee Replacement di Rumah Sakit
}

\author{
Muhajirin Maliga ${ }^{* 1,2}$, Elly Lilianty Sjattar ${ }^{3}$, Syahrul Syahrul ${ }^{4}$ \\ ${ }^{1}$ Mahasiswa Magister Ilmu Keperawatan; Fakultas Keperawatan Universitas Hasanuddin, \\ Makassar, telp: 0411586296 \\ ${ }^{2}$ Perawat Bedah; Rumah Sakit Tk. II Pelamonia, Makassar, telp: 0411314279 \\ ${ }^{3}$ Bagian Ilmu Keperawatan Medikal Bedah, FKEP UNHAS, Makassar \\ ${ }^{4}$ Bagian Keperawatan Komunitas dan Keluarga, FKEP UNHAS, Makassar \\ e-mail: *1 dandikmb2016@gmail.com, ${ }^{2}$ ellyunhas@yahoo.com, ${ }^{3}$ syahrulsaid@unhas.ac.id
}

\begin{abstract}
Abstrak
Penelitian ini bertujuan menjelaskan efektifitas edukasi terpadu dalam meningkatkan efikasi diri pasien pasca penggantian sendi panggul dan sendi lutut. Metode yang digunakan adalah database sebagai berikut: PubMed, Google Scholar, ProQuest dan Science Direct. Langkah berikutnya adalah pencarian sekunder berdasarkan referensi hasil pencarian primer terdapat 35 artikel sehingga total yang diinklusi 16 artikel.Hasil yang didapatkan setelah intervensi, peserta kelompok pemberdayaan edukasi menunujukkan secara signifikan kompetensi perawatan diri dan self-efficacy yang lebih tinggi. Setelah pemberian intervensi edukasi terpadu, terjadi peningkatan efikasi diri pasien. Dapat dilihat adanya pengaruh pada intervensi terhadap peinngkatan efikasi diri pasien pasca operasi penggantian sendi panggul dan sendi lutut.
\end{abstract}

Kata kunci-Edukasi Terpadu, Efikasi Diri, Total Hip dan Knee Replacement

\begin{abstract}
The research aimed to investigate the effectiveness of the integrated education in improving the self-efficacy of the patients post opeation of the replacements of the hip and knee joints.In the research the search was carried out using the following databases: PubMed, Google Scholar, ProQuest and Science Direct. The next step was a secondary search based on the reference to the primary search results. There were 9articles so that the total inclusion of 16 articles. The research results obtained after the intervention revealed that the participants of the education empowerment group showed significantly higher self-care competence and selfefficacy. Thus after giving an integrated educational intervention, there was an increase in the self-efficacy of the patients. It could be seen that were was an influence of the intervention on the increase of the self-efficacy of the patients after the operationsof replacemnt of the hip and knee joints.
\end{abstract}

Keywords - Integrated education, self-efficacy, Total Hip and Knee Replacement

\section{PENDAHULUAN}

Edukasi pasien adalah proses memberdayakan pasien yang dirancang agar pasien dapat bertanggung jawab atas kesehatan mereka sendiri (Falvo, 2004; Malternd, 2010; Piper, 2010). 
Sasaran edukasi ini mengarah pada program edukasi pasien yang dirancang dan bertujuan untuk mengajarkan kemampuan yang berhubungan dengan penyakit yang diderita pasien dan berfokus pada program pengendalian penyakit melalui perubahan perilaku / efikasi diri (Stoilkova, Janssen, \& Wouters, 2013) ${ }^{[1]}$

Keyakinan yang kuat mengenai efikasi diri seseorang dapat meningkatkan kemampuan dalam melakukan tindakan tertentu dengan menunjukkan perbaikan dari tindakan tersebut, sehingga menimbulkan respon yang baik (Hartley, Vance, Elliott, Cuckler, \& Berry, 2008).

Operasi TKR dianggap sebagai pengobatan yang paling efektif dalam mengobati osteoarthritis lutut stadium akhir. Jumlah TKR diperkirakan akan meningkat seiring dengan bertambahnya usia rata-rata populasi, yang mempengaruhi beban ekonomi pada masa yang akan datang (Skou et al., 2015). ${ }^{[2]}$

Pasca operasi TKR, biasanya pasien dirawat di rumah sakit selama 5-7 hari. Selama masa pemulihan, fokus utama adalah pada pemulihan kekuatan otot dan fleksi sendi lutut untuk mendapatkan kembali kemampuan fungsional mobilitas diri (Lim, Yobas, \& Chen, 2014) ${ }^{[3] .}$

Agar nyeri berkurang dan meningkatnya perbaikan fungsi fisik pada pasien OA panggul dan lutut, 28 dari 34 pedoman klinis merekomendasikan edukasi pasien (EP) dan 27 dari 34 merekomendasikan program latihan penguatan pada ekstremitas (Fernandes, Storheim, Sandvik, Nordsletten, \& Risberg, 2010). ${ }^{[4]}$

\section{METODE PENELITIAN}

Dalam kajian literatur ini, kami mengambil konsep berasal database kesehatan yang cukup baik dan bervariasi, disini pencarian dilakukan dengan menggunakan database sebagai berikut : PubMed, Google Scholar, ProQuest dan Science Direct dan PubMed dengan keyword 1 :"effectiveness education for patient (All Field)" sebanyak 210 artikel. Keyword 2 : "Selfefficacy (All Field)" sebanyak 19.789, keyword 3 : post total hip and knee replacement (All Field) sebanyak 305 artikel. selanjutnya dilakukan penggabungan keyword 1 , keyword 2 dan keyword 3 dengan filter 5 tahun terakhir (2012 - 2017) didapatkan sebanyak 1 artikel. Pencarian berikutnya di Google Scholar dengan keyword "effectiveness education for patient AND Self-efficacy AND pasca operation total hip and knee replacement" didapatkan 125 artikel, lalu dilakukan filter dari tahun 2013 - 2017 didapatkan 10 artikel. Adapun pencarian berikutnya di ProQuest dengan keyword "effectiveness education for patient AND Self-efficacy AND post total hip and knee replacement" didapatkan 12 artikel dengan filter tahun 2016 2017. Pencarian berikutnya adalah di Science Direct dengan keyword "effectiveness education for patient AND Self-efficacy AND post operation total hip and knee replacement" didapatkan 35 artikel dengan filter tahun 2017, terdapat 16 artikel yang diinklusi.

\section{HASIL DAN PEMBAHASAN}

Penelitian yang dilakukan oleh Hartley et al., (2008) dengan tujuan menguji hubungan hipotesis antara harapan dan self-efficacy dalam penanganan rehabilitasi, depresi dan kemampuan fungsional pada pasien yang menerima operasi penggantian sendi. Desain Penelitian: pada pasien dewasa $(N=100)$ yang didapatkan dari klinik ortopedi dengan diberikan kuesioner secara bertahap mengenai harapan, self-efficacy untuk rehabilitasi, nyeri, depresi, indeks massa tubuh (BMI), dan status mental 1 bulan sebelum mereka operasi penggantian sendi. Tahapan ini diselesaikan oleh 62 peserta selama 6 minggu setelah operasi. Hasil yang didapatkan adalah bahwa secara signifikan harapan dapat memprediksi depresi pre operasi, namun menurun pasca operasi yang secara otomatis dapat meningkatkan kemampuan fungsional pada saat pasca operasi. Adapun efikasi diri meningkat diikuti dengan menurunnya skor depresi pasca operasi. Sehingga dapat disimpulkan bahwa harapan dan efikasi diri meningkat pasca operasi setelah diberikan rehabilitasi serta menurunkan depresi pasien. ${ }^{[5]}$ 
Sejalan dengan penelitian yang dilakukan oleh Kearney, Jennrich, Lyons, Robinson, \& Berger, (2011) dengan tujuan membandingkan hasil pasien yang mengikuti program khusus edukasi pre operasi di rumah sakit dan yang tidak mengikuti pada pasien yang akan menjalani operasi total hip dan total knee replacement. Sampel ini terdiri dari 150 pasien yang menjalani penggantian total pinggul atau total lutut. Hasil yang didapatkan adalah pasien yang mendapatkan edukasi khusus pra operasi dilaporkan merasa lebih siap untuk operasi dan lebih mampu beradaptasi dengan nyeri yang mereka rasakan setelah operasi. Sehingga dapat disimpulkan bahwa pengetahuan yang didapat dari edukasi pra operasi rumah sakit memang mempengaruhi pengalaman pasien dalam mengatasi nyeri sehingga dapat meningkatkan efikasi diri pasien. ${ }^{[6]}$

Penelitian lain yang dilakukan oleh Huang, Sung, Wang, \& Wang, (2017) yang bertujuan untuk mengukur efektivitas program edukasi terpadu pada tahap primer (self-efficacy dan kemampuan perawatan diri) dan tahap sekunder (Aktivitas Kehidupan Sehari-hari, mobilitas, keadaan depresi dan kualitas hidup) pada kelompok orang tua yang menjalani operasi penggantian total panggul. Sampel pada penelitian ini adalah 108 peserta secara acak diberikan pada kelompok edukasi terpadu dan kelompok pembanding. Para peneliti mengumpulkan hasil data dasar saat masuk dan pada 1 hari pasca operasi, satu bulan setelah pemulangan dan tiga bulan setelah pemulangan. Hasil yang didapatkan setelah intervensi, peserta kelompok edukasi terpadu menunjukkan secara signifikan kompetensi perawatan diri dan self-efficacy yang lebih tinggi serta tingkat depresi yang lebih rendah dibandingkan dengan kelompok pembanding. Sehingga dapat disimpulkan bahwa intervensi edukasi terpadu ini sangat efektif dalam meningkatkan kemampuan yang lebih baik bagi pasien. Selain itu, melibatkan pasien dan keluarga untuk berpartisipasi dalam mengikuti program edukasi ini sangat direkomendasikan dalam mencapai hasil yang lebih baik. ${ }^{[7]}$

Penelitian lain yang dilakukan oleh Brembo, Kapstad, Van Dulmen, \& Eide, (2017) dengan tujuan untuk menentukan apakah dukungan sosial dan efikasi diri secara umum dapat memprediksi variabilitas dalam pemulihan jangka pendek pada pasien pasca THR. Sampel pada penelitian ini adalah 223 pasien yang menjalani THR pada tahun 2003-2004. Hasil yang didapatkan adalah self-efficacy yang lebih tinggi dapat meningkatkan pemulihan yang lebih baik $(\beta=-0.44[-0.87,-0.02])$. Dukungan sosial secara signifikan merupakan prediktor utama dalam meningkatkan pemulihan $(\beta=-1.40[-2.81,0.01])$. Sehingga dapat disimpulkan bahwa Efikasi diri pasien OA dan dukungan sosial dari orang lain dapat meningkatkan pemulihan setelah THR. ${ }^{[8]}$

Penelitian lain yang dilakukan oleh Tristaino et al., (2016) dengan tujuan untuk mengetahui apakah dukungan psikologis secara signifikan dapat memperbaiki pemulihan mental dan fisik pasien yang menjalani artroplasti total pinggul atau lutut primer. Sampel pada penelitian ini berjumlah 200 responden yang secara berturut-turut diberikan secara bergantian (1:1). Pada kelompok kontrol menerima perawatan rutin dan kelompok eksperimen menerima dukungan psikologis dari seorang psikolog profesional. Dukungan psikologis diberikan pada kunjungan pra-operasi, selama di ruang perawatan dan di pusat rehabilitasi. Hasil dari penelitian ini adalah pada 'Skala Komponen Mental' dari kuesioner SF-36, didapatkan hasil baik pada populasi sendi dan dua populasi pinggul dan lutut pada kelompok intervensi dan kelompok kontrol, secara signifikan kenaikan terdapat pada kelompok intervensi dibandingkan dengan kelompok kontrol ( $\mathrm{p}<0,0001$ ), dengan nilai yang umumnya lebih tinggi pada kelompok intervensi $(\mathrm{p}<0,0001)$. Pada pasien dengan artroplasti panggul, waktu rata-rata dalam mencapai hasil fisioterapi yaitu kemampuan pasien secara mandiri berjalan 50 meter dan menaiki tangga 
10 langkah adalah 6,7 $\pm 1,8$ hari (range 4-12) pada kelompok intervensi dan 7,9 $\pm 2,2$ hari (range 0-13) pada kelompok kontrol $(\mathrm{p}=0,015)$. Sehingga dapat disimpulkan bahwa terjadi penurunan tingkat kecemasan dan depresi serta kesehatan mental yang lebih baik pada kelompok pasien yang menerima dukungan psikologis (Kelompok intervensi). Pada pasien artroplasti pinggul, yang menerima dukungan psikologis mencapai tujuan fisioterapi 1,2 hari lebih awal dibandingkan dengan pasien dalam kelompok kontrol $(p=0,0015)$. ${ }^{[9]}$

Penelitian lain yang dilakukan oleh Saw, Kruger-Jakins, Edries, \& Parker, (2016) dengan tujuan mengeksplorasi efek dari latihan fisioterapi selama enam minggu dan intervensi edukasi nyeri pada pasien pasca artroplasti. Sampel dalam penelitian ini adalah 74 peserta dari daftar tunggu artroplasti dipilih secara acak yaitu untuk intervensi $(n=35)$ dan kelompok kontrol $(n=$ 39). Intervensi diberikan dalam enam sesi latihan, pada kelompok intervensi diberikan fisioterapi (edukasi dua jam/minggu, latihan dan relaksasi). Kelompok kontrol menerima perawatan biasa. Hasil penelitian ini adalah menunjukkan bahwa kelompok intervensi mengalami perbaikan signifikan dibandingkan dengan kelompok kontrol dengan ukuran efek standar (ES) pada tingkat nyeri [minggu 6: $\mathrm{p}<0,01, \mathrm{ES}=0,94,95 \% \mathrm{CI}(0,45-1,41)$, bulan 6: $\mathrm{p}=$ $0,02$. ES $=0,74,95 \%$ CI $(0,26-1,2)]$ adapun efek sedang hingga tinggi pada tingkat nyeri [minggu 6: $\mathrm{p}<0,01, \mathrm{ES}=1,2,95 \% \mathrm{CI}(0,70-1,69)$, minggu 12: $\mathrm{p}=0,04, \mathrm{ES}=0,68,95 \% \mathrm{CI}$ $(0,20-1,14)$, bulan 6: $\mathrm{p}<0,01, \mathrm{ES}=0,98,95 \% \mathrm{CI}(0,49-1,45)]$. Terdapat $53 \%$ dari responden melaporkan bahwa tindakan intervensi meningkatkan cara mengatasi rasa nyeri mereka. Sehingga dapat disimpulkan bahwa intervensi yang diberikan dapat meningkatkan secara signifikan kemandirian pasien dalam mengatasi nyeri. ${ }^{[10]}$

\section{KESIMPULAN}

Secara luas edukasi pasien merupakan salah satu komponen dalam keperawatan yang secara signifikan memiliki efek hubungan timbal balik antara pasien dan perawat. Oleh karena itu edukasi dipandang sebagai cara dalam memotivasi seseorang dalam memiliki tanggung jawab yang lebih besar demi meningkatkan kesehatan mereka sendiri, dengan demikian mengurangi beban berat pada pelayanan keperawatan (Jamaati, Kashafi, Vahedian-azimi, \& Asghari-jafarabadi, 2013) ${ }^{[11]}$

Dalam menentukan self-efficacy, seorang individu harus memiliki kesempatan untuk mengevaluasi diri atau kemampuannya untuk membandingkan output individu sebagaimana kriteria evaluasi. Hal ini merupakan proses perbandingan yang memungkinkan seorang individu dalam menilai kemampuan kinerja dan membangun ekspektasi efikasi diri (Peterson \& Bredow, 2013; Smith \& Liehr, 2014). ${ }^{[12]}$

Self-efficacy memiliki dampak pada reaksi emosional individu dan pola pikir. Selfefficacy juga dapat digambarkan sebagai fungsi keyakinan diri dengan individu yang dapat menyelesaikan suatu tugas. Self-efficacy yang lebih tinggi dalam suatu bidang sangat berkaitan dengan hasil yang baik, mulai dari kepuasan kerja dan kinerja yang lebih tinggi, untuk kesehatan fisik dan mental yang lebih baik, untuk kinerja akademik yang lebih baik (Cherian \& Jacob, 2013) ${ }^{[13]}$

Bandura berpendapat bahwa self-efficacy mempengaruhi pilihan yang dibuat orang, cara mereka bertindak, upaya yang mereka lakukan, ketekunan dan keseriusan mereka. Selain mempengaruhi perilaku seseorang, keyakinan self-efficacy juga mempengaruhi pikiran dan perasaan seseorang. Individu dengan self-efficacy yang kurang cenderung berpikir bahwa tugastugas yang diberikan tampak lebih sulit dijalani (Bin Hasan, Bin Hossain, \& Islam, 2014) ${ }^{[14]}$.

Setelah intervensi pemberian edukasi terpadu, terjadi peningkatan efikasi diri pasien. Dapat dilihat adanya pengaruh pada intervensi terhadap peningkatan efikasi diri pasien pasca operasi penggantian sendi panggul dan sendi lutut. 


\section{SARAN}

Institusi pendidikan diharapkan dapat menjadikan edukasi terpadu dalam hal ini rehabilitasi sebagai bahan pembelajaran pada praktik profesi untuk pasien di rumah sakit. Selain itu, rumah sakit diharapkan mampu memberi dan memfasilitasi pelatihan edukasi terpadu pada perawat terutama di ruang perawatan yang memiliki pasien bedah ortopedi agar dapat meningkatkan kemandirian pasien pasca operasi ortopedi. Literatur review ini memerlukan penelitian yang lebih lanjut dengan intervensi lain yang lebih lama dan jumlah sampel yang lebih banyak.

\section{UCAPAN TERIMA KASIH}

Penulis mengucapkan terima kasih kepada Direktur Jenderal Kekuatan Pertahanan Kementerian Pertahanan Republik Indonesia yang telah memberi beasiswa serta dukungan financial terhadap penelitian ini.

\section{DAFTAR PUSTAKA}

[1] Stoilkova, A., Janssen, D. J. A., \& Wouters, E. F. M. (2013). Educational programmes in COPD management interventions: A systematic review. Respiratory Medicine, 107(11), 1637-1650. https://doi.org/10.1016/j.rmed.2013.08.006

[2] Skou, S. T., Roos, E. M., Laursen, M. B., Rathleff, M. S., Arendt-Nielsen, L., Simonsen, O., \& Rasmussen, S. (2015). A Randomized, Controlled Trial of Total Knee Replacement. New England Journal of Medicine, 373(17), 1597-1606. https://doi.org/10.1056/NEJMoa1505467

[3] Lim, Y. C., Yobas, P., \& Chen, H. C. (2014). Efficacy of relaxation intervention on pain, self-efficacy, and stress-related variables in patients following total knee replacement surgery. Pain Management Nursing, 15(4), 888-896. https://doi.org/10.1016/j.pmn.2014.02.001

[4] Fernandes, L., Storheim, K., Sandvik, L., Nordsletten, L., \& Risberg, M. A. (2010). Efficacy of patient education and supervised exercise vs patient education alone in patients with hip osteoarthritis: A single blind randomized clinical trial. Osteoarthritis and Cartilage, 18(10), 1237-1243. https://doi.org/10.1016/j.joca.2010.05.015

[5] Hartley, S. M., Vance, D. E., Elliott, T. R., Cuckler, J. M., \& Berry, J. W. (2008). Hope, Self-Efficacy, and Functional Recovery After Knee and Hip Replacement Surgery. Rehabilitation Psychology, 53(4), 521-529. https://doi.org/10.1037/a0013121

[6] Kearney, M., Jennrich, M. K., Lyons, S., Robinson, R., \& Berger, B. (2011). Effects of preoperative education on patient outcomes after joint replacement surgery. Orthopaedic Nursing, 30(6), 391-396. https://doi.org/10.1097/NOR.0b013e31823710ea

[7] Huang, T.-T., Sung, C.-C., Wang, W.-S., \& Wang, B.-H. (2017). The effects of the empowerment education program in older adults with total hip replacement surgery. ARPN Journal of Engineering and Applied Sciences, 12(10), 3218-3221. https://doi.org/10.1111/ijlh.12426 
[8] Brembo, E. A., Kapstad, H., Van Dulmen, S., \& Eide, H. (2017). Role of self-efficacy and social support in short-term recovery after total hip replacement: A prospective cohort study. Health and Quality of Life Outcomes, 15(1), 1-10. https://doi.org/10.1186/s12955-017-0649-1

[9] Tristaino, V., Lantieri, F., Tornago, S., Gramazio, M., Carriere, E., \& Camera, A. (2016). Effectiveness of psychological support in patients undergoing primary total hip or knee arthroplasty: a controlled cohort study. Journal of Orthopaedics and Traumatology, 17(2), 137-147. https://doi.org/10.1007/s10195-015-0368-5

[10] Saw, M. M., Kruger-Jakins, T., Edries, N., \& Parker, R. (2016). Significant improvements in pain after a six-week physiotherapist-led exercise and education intervention, in patients with osteoarthritis awaiting arthroplasty, in South Africa: A randomised controlled trial. BMC Musculoskeletal Disorders, 17(1), 1-14. https://doi.org/10.1186/s12891-016-1088-6

[11] Jamaati, H., Kashafi, M. B., Vahedian-azimi, A., \& Asghari-jafarabadi, M. (2013). Patient Education problems in Clinical and Educational Settings: A Review and Mixed methods Study. International Journal of Medical Reviews, 1(3), 133-141. Retrieved from http://journals.bmsu.ac.ir/ijmr/index.php/ijmr/article/download/54/94.

[12] Peterson, S. J., \& Bredow, T. S. (2013). Middle Range Theories. Application to nursing research. (Third). New York: Wolter Kluwer.

[13] Cherian, J., \& Jacob, J. (2013). Impact of Self Efficacy on Motivation and Performance of Employees. International Journal of Business and Management, 8(14), 80-88. https://doi.org/10.5539/ijbm.v8n14p80

[14] Bin Hasan, M. Z., Bin Hossain, M. T., \& Islam, M. A. (2014). Factors affecting selfefficacy towards academic performance: A study on polytechnic students in Malaysia. Advances in Environmental Biology, 8(9 SPEC. ISSUE 4), 695-705. Retrieved from ttp://www.aensiweb.com/aeb.html 